\title{
BMJ Open Labour market attachment after mild traumatic brain injury: nationwide cohort study with 5-year register follow- up in Denmark
}

\author{
Heidi Jeannet Graff, ${ }^{1}$ Volkert Siersma, ${ }^{2}$ Anne Møller, ${ }^{2,3}$ Jakob Kragstrup, ${ }^{2}$ \\ Lars L Andersen, ${ }^{4}$ Ingrid Egerod, ${ }^{5}$ Hana Malá Rytter ${ }^{6,7}$
}

To cite: Graff HJ, Siersma V, Møller A, et al. Labour market attachment after mild traumatic brain injury: nationwide cohort study with 5-year register followup in Denmark. BMJ Open 2019;9:e026104. doi:10.1136/ bmjopen-2018-026104

- Prepublication history for this paper is available online. To view these files, please visit the journal online (http://dx.doi. org/10.1136/bmjopen-2018026104).

Received 17 August 2018 Revised 12 March 2019 Accepted 13 March 2019

\section{SLinked}

http://dx.doi.org/10.1136/ bmjopen-2018-027297

Check for updates

(C) Author(s) (or their employer(s)) 2019. Re-use permitted under CC BY-NC. No commercial re-use. See rights and permissions. Published by BMJ.

For numbered affiliations see end of article.

Correspondence to Heidi Jeannet Graff; heidi.graff@supermail.dk

\section{ABSTRACT}

Objectives Sickness absence after mild traumatic brain injury (mTBl) is frequent due to postconcussive symptoms. We examined labour market attachment following mTBI up to 5 years postinjury.

Design and setting Nationwide cohort study with register follow-up.

Participants Patients between 18 and 60 years with mTBI (International Classification of Diseases, version 10 diagnosis S06.0) were extracted from the Danish National Patient Register ( $n=19$ 732). Controls were matched on sex, age and municipality $(n=18640)$. Patients with spinal cord and column injuries, traumatic brain injury and concussions 5 years preinjury or as secondary diagnosis to the concussion in the inclusion period were excluded.

Primary and secondary outcome measures Data were extracted from the Danish Register for Evaluation of Marginalization. Primary outcome was 'not attending ordinary work' defined as receiving any social transfer payment. Secondary outcomes were health-related benefits, limited attachment to the labour market, permanent lack of attachment to the labour market and death.

Results 5 years after diagnosis, $43 \%$ of patients were not attending ordinary work. The odds increased from 6 months (OR 1.30, 95\% Cl 1.24 to 1.36) to 5 years (OR $1.54,95 \% \mathrm{Cl} 1.45$ to 1.63$)$. The odds of health-related benefits were $32 \%(\mathrm{OR} 1.32,95 \% \mathrm{Cl} 1.22$ to 1.42$)$ at 6 months and $22 \%(0 \mathrm{R} 1.22,95 \% \mathrm{Cl} 1.12$ to 1.33$)$ at 5 years. Limited attachment to the labour market showed increased odds at 5 years (OR 1.38, 95\% Cl 1.27 to 1.51) and the odds of permanent lack of attachment to the labour market were higher for patients compared with controls (OR 2.59, $95 \% \mathrm{Cl} 2.30$ to 2.92). Death was more than two times higher at 5 years postinjury (OR 2.62, $95 \% \mathrm{Cl} 2.10$ to 3.26 ).

Conclusions $43 \%$ of concussed patients were not attending ordinary work 5 years postinjury and received health and social transfer benefits. We conclude that mTBI has a long-term impact on labour market attachment. Prevention and treatment of persisting postconcussive symptoms should be considered.

Trial registration number NCT03214432; Results
Strengths and limitations of this study

- This was a nationwide cohort study with register-based follow-up including 20000 patients with mild traumatic brain injury (mTBI).

- The data were extracted from high-quality Danish national registers.

- This study estimated the prevalence and OR of not attending ordinary work, health-related benefits and death in patients with mTBI up to 5 years postinjury.

- This study had no access to patient records, with the inherent risk of misclassification.

\section{INTRODUCTION}

Mild traumatic brain injury (mTBI) is a common neurological disease defined as an acute brain injury resulting from mechanical energy to the head from external physical force. Operational criteria include at least one of following: confusion or disorientation, loss of consciousness, posttraumatic amnesia (<24hours), transient neurological abnormalities, absence of intracranial lesions not requiring surgery and Glasgow Coma Scale score of $13-15$ postinjury. ${ }^{1}$ Concussion (commotio cerebri) represents an entity, that is, grouped under mTBI, although the pathophysiology behind may be dissimilar and heterogeneous. The differentiation remains elusive due to the usual absence of objective findings on conventional imaging. The clinical diagnosis of concussion is based on short-lasting alteration of consciousness and presence of posttraumatic amnesia and confusion. ${ }^{23}$ Despite recent efforts to improve the clinical diagnostic process, ${ }^{4}{ }^{5}$ accurate diagnosis of mTBI is still a challenge due to frequent confounding factors.

Approximately $70 \%-90 \%$ of all traumatic brain injuries (TBIs) fall into the category of mTBI. ${ }^{6-8}$ The incidence of hospital-treated and emergency-treated patients is 50-300 
cases per 100000 people in the USA, Scandinavia and Australia $^{89}$ and more frequent among young people and men. ${ }^{8}$ However, these numbers probably fall short as studies also show numbers $>700$ cases per 100000 people per year. ${ }^{8}$

Numerous studies have examined postconcussive symptoms in adults showing symptoms like dizziness, fatigue, insomnia, posttraumatic headache and memory and concentration difficulties ${ }^{10-12}$ leading to long-term sickness and absence from work. Postconcussive symptoms result in an increased use of general practice services the first year postinjury, as reported by a Danish study. ${ }^{13}$ In $15 \%$ of patients with mTBI, postconcussive symptoms are persistent (>12 months postinjury). ${ }^{14}{ }^{15}$ Additionally, several risk factors are associated with persisting symptomatology, such as female gender, premorbid physical or psychiatric comorbidities, injury-related conditions, previous head injury, psychological distress, and drug and alcohol abuse. ${ }^{12} 1617$

Most patients return to work (RTW) within the first couple of months after mTBI, but a small proportion of patients is unable to RTW due to disability. ${ }^{18}{ }^{19}$ Cancelliere et al found that most patients $(>75 \%)$ had returned to work after 6 months and $5 \%$ were on social transfer payments 2 years postinjury. ${ }^{20}$

RTW has been conceptualised as being a dynamic process with different related outcomes of labour market attachment or time off work, but also outcomes related to the process of RTW such as psychological functioning and job satisfaction. ${ }^{21}{ }^{22}$ RTW after mTBI has been suggested to depend on multiple factors such as injury-related factors, ${ }^{20}$ premorbid demographics such as younger age,${ }^{18}$ workplace-related factors such as support, ${ }^{23}$ and influence on work planning ${ }^{24}$ and patient characteristics such as psychosocial status. ${ }^{25}$ These studies have methodological limitations in study design which complicate evaluation of evidence regarding the magnitude of the problem. They have small sample sizes, are not representative, ${ }^{10}$ are based on self-reported data and have short follow-up and considerable dropout leading to attrition bias. ${ }^{19}$ The present analysis overcomes these challenges by using Danish nationwide administrative data to examine a larger, representative sample and to perform long-term follow-up. This study is concerned with labour market attachment in hospital-treated patients receiving the diagnosis concussion (commotio cerebri) as the only brain injury diagnosis.

We examined a comprehensive range of postinjury transitions in the labour market aiming at analysing attachment to the labour market up to 5 years after mTBI using a portfolio of outcomes, including a variation of social transfer payments and data on permanent lack of attachment to the labour market and death.

\section{METHODS}

The data used in the present analyses are obtained by linking several Danish national registers through the unique personal identification number, the central personal registry number (CPR number) assigned to all Danish citizens at birth or immigration, provided by the Danish Civil Registration System. ${ }^{26}$

\section{Study population}

The study was a nationwide population-based cohort study of all mTBI cases in Denmark in the 5-year inclusion period 1 January 2003-31 December 2007. Cases were identified in the Danish National Patient Register (DNPR) which contains information on all inpatient and outpatient contacts in Danish secondary care. ${ }^{27}$ Notably, it codes each contact with International Classification of Diseases, version 10 (ICD-10) diagnosis codes. Patients with $\mathrm{mTBI}$ were included in the cohort based on their index date, the date of their first entry in the DNPR in the inclusion period with concussion (ICD-10 code S06.0) as primary diagnosis, excluding patients with diagnosis (primary or secondary) of cerebral oedema, diffuse and focal brain injury, subdural, epidural and subarachnoid haemorrhage, crushing injury and fracture of head, neck, skull, face and facial bones, and injuries of brain and cranial nerves in the inclusion period. ${ }^{9}$ Included patients with mTBI were working-age adults between 18 and 60 years available for the labour market on the index date; the upper limit was set because individuals in Denmark older than 60 years are entitled to early retirement, if they have paid for such a scheme. ${ }^{28}$ Availability for the labour market was defined as gainful employment or receiving unemployment benefits, but actively job seeking (see figure 1). Furthermore, they were not hospital treated or diagnosed with other major neurological injuries such as spinal cord and column injuries ${ }^{29}$ and TBI (including concussion) ${ }^{9}$ in the 5-year period 1 January 1998-31 December 2002 before the inclusion period ${ }^{930}$ since previous brain injury and neurological problems are found to be associated with prolonged symptoms. ${ }^{31}$ Finally, patients were not included if they had lived outside of Denmark at any time during the inclusion period and the 5-year period before.

For each mTBI case in the cohort, a control was randomly selected from the population register. Controls had similar inclusion criteria as the cases, but they had no diagnosis of concussion during the inclusion period 1 January 2003-31 December 2007.

The control was matched to the case on sex, municipality and age (year of birth \pm 0.5 years, expanded to 1 and 2 years in case of no initial match) (see figure 1). The same exclusion criteria were applied for the selection of controls.

Availability for the labour market was assessed from the Danish Register for Evaluation of Marginalization (DREAM), containing weekly information on all individuals receiving any social public transfer payments. ${ }^{32}$ Patients and their matching controls were excluded from the cohort if there were any major neurological injuries ${ }^{92}$ as secondary diagnoses at the index date, they were unavailable for the labour market, they had unknown residence or were inhabitants of Greenland. 


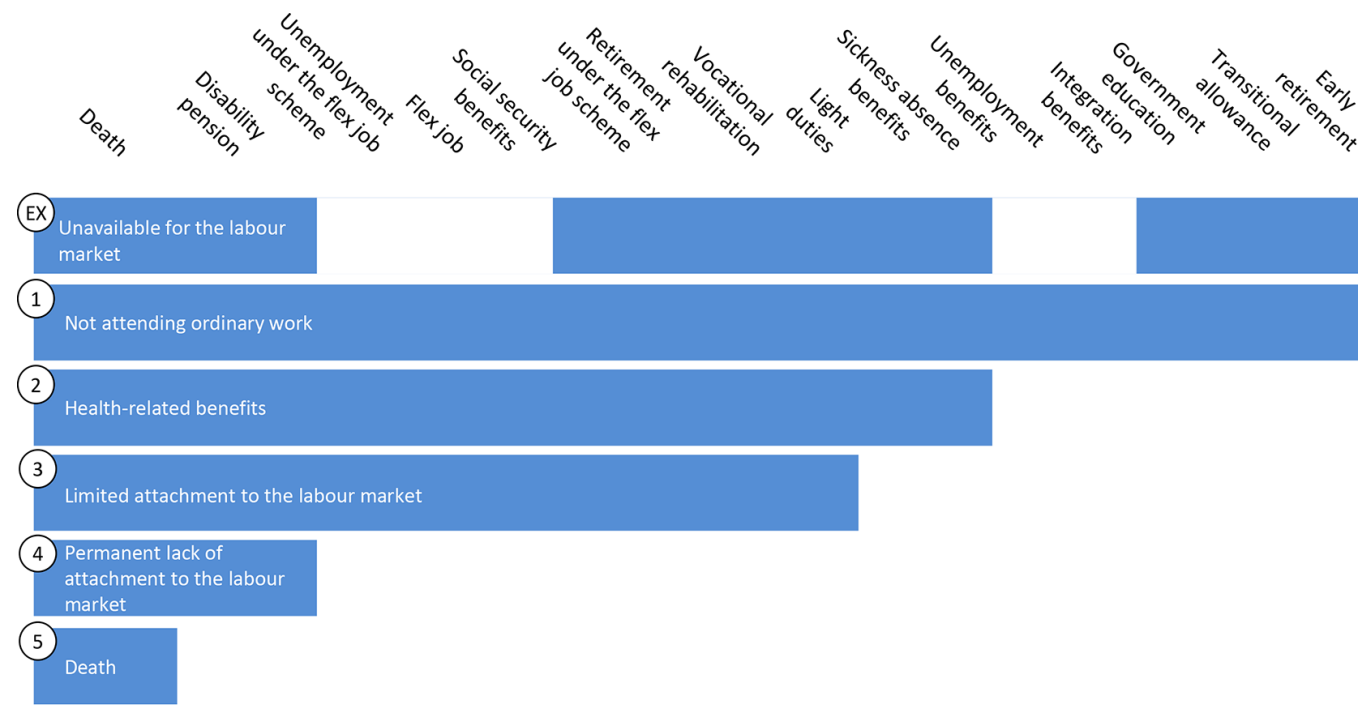

* EX is the exclusion criterion "unavailable for the labour market", assessed at one week before trauma.

Figure 1 Description of social transfer payments as part of the Danish welfare system. Categories describe unavailable for the labour market (an exclusion criterion) (EX), the primary outcome (1) and the secondary outcomes (2-5) in terms of the different social transfer payments and other social conditions (first row) that are included in each.

\section{Outcome measures}

The outcomes of the present analyses were assessments of variations in attachment to the labour market evaluated in the DREAM database (figure 1) the week before the case's index date, and at 6 months, 12 months, 2 years and 5 years after the case's index date (figure 1 ).

\section{Not attending ordinary work}

'Not attending ordinary work' was the primary outcome and was indicated by any entry in DREAM, that is, receiving any social transfer payment, such as unemployment benefits unrelated to the subject's health condition, sickness absence benefits, social benefits granted, shortterm and long-term sickness or death. If there was no DREAM entry, it was assumed that the subject was gainfully employed or self-supporting at that time (figure 1).

The set of secondary outcomes are defined increasingly narrower than the primary outcome and focus on attachment to the labour market due to health conditions. At the time of the current study, employers in Denmark were obliged to finance sickness benefits for the first 30 days. Sickness benefits lasting $>4$ consecutive weeks were to be compensated by the Danish municipalities. ${ }^{33}$ Sick-listed individuals could receive sickness benefits for a maximum of 1 year. ${ }^{34}$ If individuals were not able to return to ordinary work due to long-term limited work capacity, a partial RTW at lower capacity was possible with a 'flex job'. If the sick-listed individual was not able to RTW at all, the municipality could grant disability pension. ${ }^{35} 36$ The grading of the outcomes is illustrated in figure 1 .

\section{Health-related benefits}

Health-related benefits were indicated by DREAM entries given for short-term or long-term restrictions in attachment to the labour market due to health conditions (excluding unemployment benefits unrelated to the subject's health condition). These were sickness absence benefits, vocational rehabilitation, flex job, unemployment benefits specifically granted to citizens on flex job, social security benefits, light duties, disability pension and death.

\section{Limited attachment to the labour market}

Social transfer payments due to limited attachment to the labour market were indicated by DREAM entries given for reduced work capacity and thereby long-term restrictions in attachment to the labour market due to health conditions (excluding sickness absence benefits compared with secondary outcome 2 ). These were vocational rehabilitation, flex job, unemployment benefits specifically granted to citizens on flex job, social security benefits, light duties, disability pension and death.

\section{Permanent lack of attachment to the labour market}

Permanent lack of attachment to the labour market was indicated by DREAM entries given for permanent withdrawal from the labour market due to health conditions. These were disability pension and death.

\section{Death}

Death was indicated by the DREAM entry for death.

\section{Potential confounders}

Sex, age and municipality at the index date were obtained from the population register linked to the DNPR. The municipality information was categorised into five regions reflecting Denmark's reform of local government structure from $2007 .{ }^{37}$ From the index date, calendar year and season were derived. Calendar year was included in the model as a previous study found increasing odds of 
returning to work during the study period..$^{38}$ The reason could be a change in diagnostic practice and the Danish sickness benefit act becoming more effective over the years. Seasonal variation was considered a confounder, as a previous study suggested that TBI is associated with season-specific activities and most pronounced during fall and winter. ${ }^{39}$ Preinjury income was measured at the index date and taken as personal gross income including revenue and social transfer income and was obtained from the Income Statistics Register. ${ }^{40}$ Income was divided into four income groups: $<100000,100$ 000-200 000, $200 \quad 000-300 \quad 000$ and $>300000 \mathrm{Kr}$ roughly reflecting the quartiles in the present cohort. Information on the highest attained educational level was obtained from the Danish Education Register ${ }^{41}$ and was categorised into three educational groups: low education (primary education), medium education (lower and upper secondary education, post-secondary-non-tertiary education) and high education (short-cycle tertiary education, bachelor, master, doctoral or equivalent). Information on cohabitation status and ethnic origin was obtained from the Danish Family Relations Database ${ }^{2642}$ and was categorised into married or cohabiting couple and single, and as Danish born and not Danish born, respectively. Preinjury illness burden was measured by Charlson comorbidity index (CCI), a weighted sum of 19 indicators for selected diagnoses. ${ }^{43}$ For the present CCI evaluation, a diagnosis was indicated for an individual when a corresponding ICD-10 code was encountered in the DNPR in the 5 -year period 1 January 1998-31 December 2002 before the inclusion period. Psychiatric diagnoses are not incorporated in CCI but are possible confounders related to both labour market attachment and an increased risk of TBI. ${ }^{45} 46$ Hence, information on psychiatric diagnoses separately from CCI was obtained from the DNPR (any ICD-10 Classification of Mental and Behavioural Disorders indicated as $\mathrm{F}$ diagnosis) over the same 5-year period.

\section{Statistical analysis}

Baseline covariates at the index date, and the outcomes at the index date and the follow-up time points were reported as numbers and percentages separately for mTBI patients and their matched controls. Raw comparisons of the baseline covariates between the mTBI patients and their controls are done by $\chi^{2}$ tests.

The difference in tendency of some degree of decreased attachment to the labour market, between patients with mTBI and their controls, at each of the index date and the four follow-up time points, was assessed by OR and corresponding 95\% CI from a multivariable logistic regression model; an OR $>1$ implied higher odds for the mTBI group. The model was parameterised so that the assessments at the four follow-up time points were adjusted for differences already present at the index date, that is, preinjury differences. Hence, the assessment at the index date can be viewed as an assessment of the employment aspect of a social gradient in mTBI incidence; the assessments at the follow-up time points report on the short-term and long-term differences in attachment attributable to mTBI. Results are reported both unadjusted and adjusted for the potential confounders: age, gender, municipality, seasonal variation, calendar year, education, income, cohabitation status, ethnicity, preinjury comorbidities and preinjury psychiatric diagnosis. Inference was done by generalised estimating equations to adjust for repeated measurement and matching.

Subjects with missing values in one of the covariates were omitted from analyses where these covariates were included. P values $<0.05$ were considered statistically significant. SAS V.9.4 was used for statistical analysis.

\section{Patient and public involvement}

Patients and the public were not involved in the design and the conduct of the study.

\section{RESULTS}

\section{Baseline characteristics of the population}

Nineteen thousand seven hundred and thirty-two patients with mTBI were eligible for the cohort and 18640 matching controls were included in the study. In some cases, notably with patients from small municipalities, it was not possible to find a matching control, see figure 2. Overall, the cohort was characterised by a weak tendency in patients with mTBI to have lower education, lower income, being married or cohabiting and having a higher prevalence of preinjury diseases (both somatic diseases as captured by CCI and psychiatric diseases) compared with their matched controls (table 1).

\section{Analysis of attachment to labour market}

Table 2 shows the prevalence for each outcome for patients and controls during 5 years of follow-up.

\section{Primary outcome}

\section{Not attending ordinary work}

It can be seen from table 2 and figure 3 that patients compared with controls had an overall higher increase of not attending ordinary work from the index date $(32 \%$, $27 \%$ ) to 5 years postinjury $(43 \%, 30 \%$ ) (table 2 and figure 3). Compared with the secondary outcomes, the prevalence was higher for not attending ordinary work which included social transfer payments that were not health related. For the unadjusted model, there were $25 \%$ higher odds of not attending ordinary work (OR $1.25,95 \%$ CI 1.19 to 1.30 ) for patients compared with controls at the index date. However, for the adjusted model, no differences were seen between groups at the index date. During the 5-year follow-up, the odds of not attending ordinary work increased, and at 5 years the odds were $54 \%$ higher (OR 1.54, 95\% CI 1.45 to 1.63 ) among patients with mTBI (table 2 and figure 3 ) compared with controls. 
$(n=24$ 093)

Hospital admitted, emergency department or outpatient treated patients with concussion (ICD-10 S06.0) between 2003 and 2007, age $18-60$ years

No major neurological injuries or concussion between 1998 and 2002 and no external stay out of Denmark between 1998 and 2007.

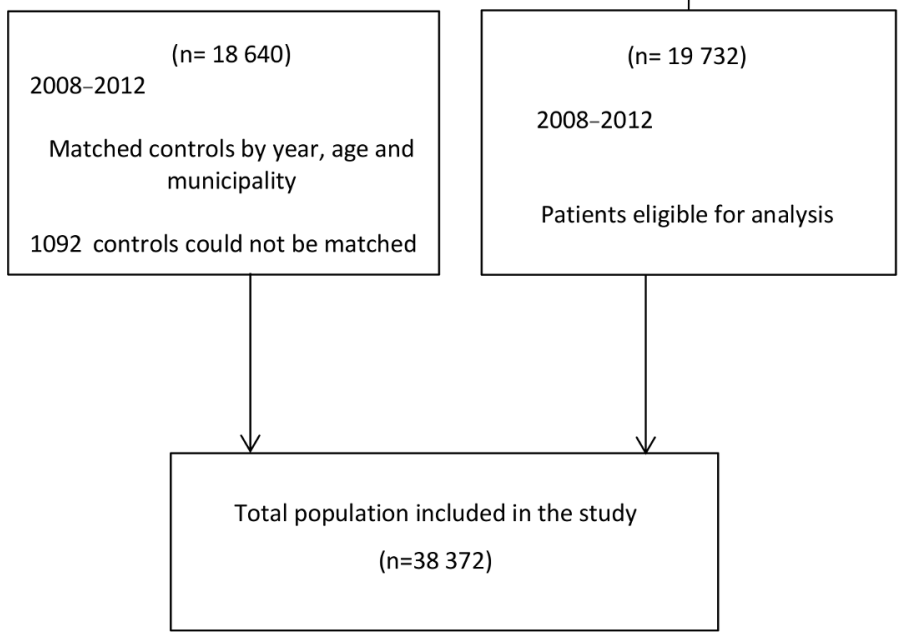

Excluded $(\mathrm{n}=4361)$

2003-2007

- Major neurological injuries ( $n=522)$

- Unknown residence $(n=19)$

- Living in Greenland $(n=5)$

- Not available for work or not gainfully occupied $(n=3911)$

Figure 2 Inclusion of the study population. ICD-10, International Classification of Diseases, version 10.

\section{Secondary outcomes}

\section{Health-related benefits}

The overall prevalence of health-related benefits was significantly higher for patients (11\%) compared with controls $(4 \%)$ at the index date, and the difference between groups continued during follow-up. The odds of health-related benefits were more than two times higher (OR 2.07, 95\% CI 1.90 to 2.25) at the index date even after adjustment for potential socioeconomic confounders and the odds of health-related benefits continued to stay elevated during follow-up (table 2).

\section{Limited attachment to the labour market}

For social transfer payments related to limited attachment to the labour market, the prevalence was also higher for patients (11\%) compared with controls (4\%) at the index date and slightly increased during follow-up. The adjusted OR was almost two times higher at the index date for patients compared with controls (OR 1.92, 95\% CI 1.76 to 2.10). However, the long-term effect of mTBI on limited attachment to the labour market was most pronounced at 2 and 5 years.

\section{Permanent lack of attachment to the labour market}

During follow-up, a higher prevalence of permanent lack of attachment to the labour market was seen in patients compared with controls, which increased from 6 months to 5 years. At 6 months, the adjusted odds for permanent lack of attachment to the labour market was almost two times higher for patients (OR 1.90, 95\% CI 1.36 to 2.66) and the long-term perspective continued showing large effect.

\section{Death}

The prevalence of death was higher among patients showing an increase from $0.30 \%$ at 6 months to $2.42 \%$ at 5 years. The adjusted odds for death for patients with mTBI was sixfold increased at 6-month follow-up (OR $6.3795 \%$ CI 2.71 to 14.95 ) and the long-term effects continued to be large but diminishing during follow-up.

\section{DISCUSSION}

We examined short-term and long-term labour market attachment in a large cohort of working-age patients with mTBI up to 5 years postinjury compared with the general 
Table 1 Social and preinjury health characteristics of patients with $\mathrm{mTBI}$ and controls

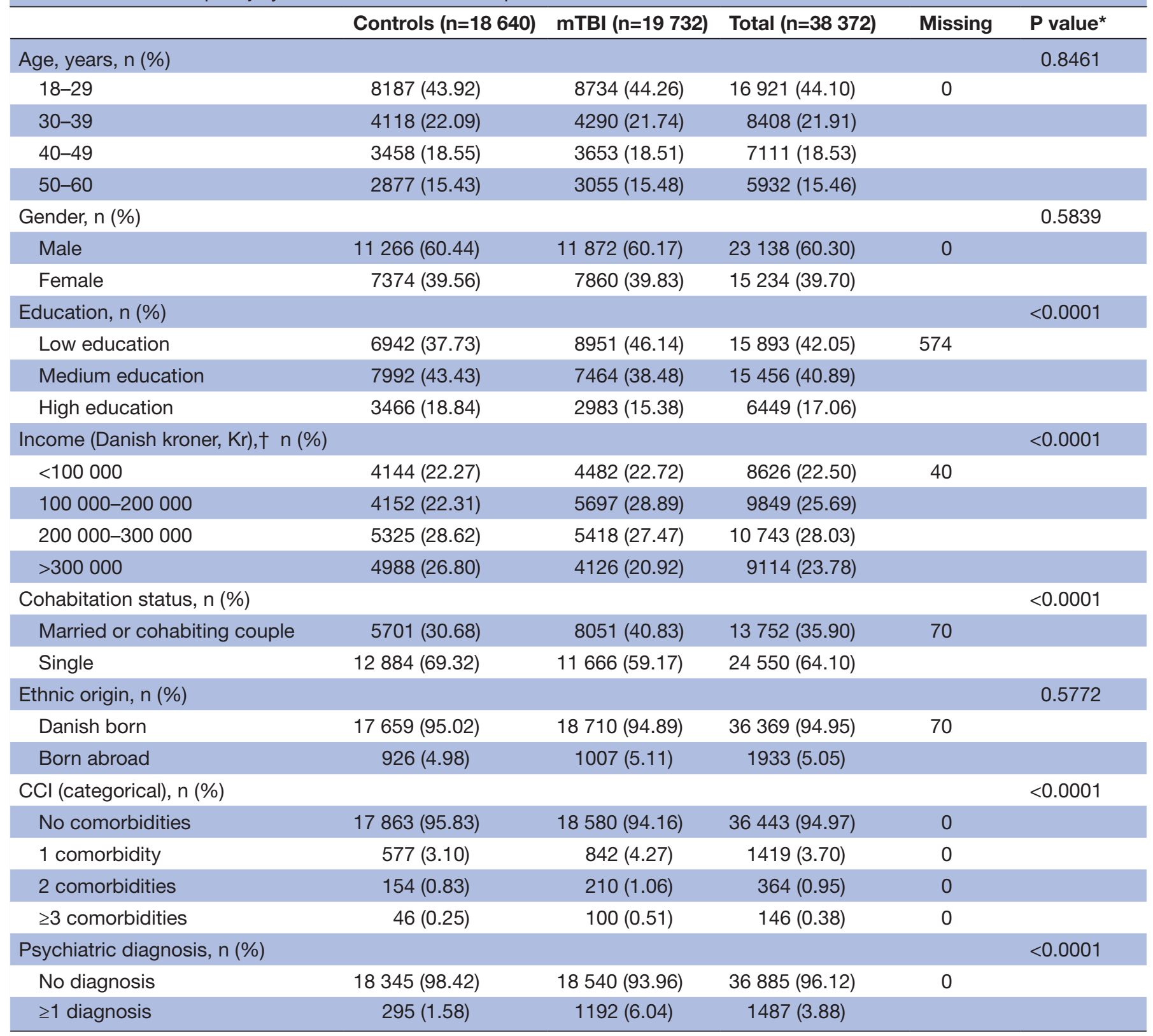

${ }^{*} \mathrm{P}$ value from a Pearson's $\chi^{2}$ test.

†Currency exchange rate of May 2018: $1 €=7.44834 \mathrm{Kr}$.

$\mathrm{CCl}$, Charlson comorbidity index; $\mathrm{mTBI}$, mild traumatic brain injury.

population. The proportion of $\sim 20000$ included patients in this study are difficult to compare to previous studies, since these mostly report incidence rates. ${ }^{8}$ However, a Danish study included 10000 patients in 1994 and 2002, ${ }^{9}$ and another Danish register-based study included $~ 90$ 000 patients during a 13-year follow-up period. ${ }^{13}$

We found that attachment to the labour market varied between patients and controls at the date of injury. The odds of not attending ordinary work were increased by $25 \%$ and remained higher for patients during the 5-year follow-up (of about 40\%). A social gradient in not attending ordinary work at the index date could be suspected, as patients had a significantly lower educational level, income and more comorbidities compared with controls (see table 1). Our findings agree with a Danish register-based cohort study ${ }^{13}$ demonstrating that individuals with mTBI had a higher use of general practice even 5 years before mTBI. However, when we controlled for socioeconomic factors, comorbidities and psychiatric diagnoses, there were no difference in the odds of not attending ordinary work between the two groups in our sample at index date. Yet, the adjusted odds of not attending ordinary work remained increased by 30\%-50\% during the 5-year follow-up. This strongly supports that mTBI is the incident leading to not returning to work. 
Table 2 Prevalence of labour market attachment and death in patients with mTBI and controls at 6 and 12 months and 2 and 5 years postinjury

\begin{tabular}{|c|c|c|c|c|c|c|}
\hline & $\begin{array}{l}\text { Controls }(n=18 \\
640)^{*}\end{array}$ & mTBI $(n=19732)^{*}$ & $\begin{array}{l}\text { Crude OR } \\
(95 \% \mathrm{Cl})\end{array}$ & $P$ value & $\begin{array}{l}\text { Adjusted OR } \\
(95 \% \mathrm{Cl}) \dagger\end{array}$ & $P$ value \\
\hline \multicolumn{7}{|c|}{ Not attending ordinary work } \\
\hline 6 months, $\mathrm{n}(\%)$ & $5107(27.40)$ & 7289 (36.94) & 1.24 (1.20 to 1.29$)$ & $<0.0001$ & 1.30 (1.25 to 1.36$)$ & $<0.0001$ \\
\hline 12 months, n (\%) & 4898 (26.28) & $7149(36.23)$ & 1.28 (1.22 to 1.33$)$ & $<0.0001$ & 1.35 (1.28 to 1.42$)$ & $<0.0001$ \\
\hline \multicolumn{7}{|c|}{ Health-related benefits } \\
\hline Index date, n (\%) & $795(4.27)$ & $2230(11.30)$ & 2.85 (2.62 to 3.10$)$ & $<0.0001$ & 2.07 (1.90 to 2.25$)$ & $<0.0001$ \\
\hline 6 months, $\mathrm{n}(\%)$ & $1120(6.01)$ & $3600(18.24)$ & $1.21(1.13$ to 1.29$)$ & $<0.0001$ & $1.32(1.22$ to 1.42$)$ & $<0.0001$ \\
\hline 12 months, n (\%) & $1197(6.42)$ & $3584(18.16)$ & $1.12(1.04$ to 1.20$)$ & 0.0020 & 1.22 (1.13 to 1.32$)$ & $<0.0001$ \\
\hline Index date, n (\%) & $795(4.27)$ & $2230(11.30)$ & 2.86 (2.64 to 3.11$)$ & $<0.0001$ & 1.93 (1.76 to 2.10$)$ & $<0.0001$ \\
\hline 6 months, $\mathrm{n}(\%)$ & $816(4.38)$ & $2326(11.79)$ & 1.01 (0.95 to 1.08$)$ & 0.8162 & 1.02 (0.96 to 1.09$)$ & 0.5123 \\
\hline 12 months, n (\%) & $846(4.54)$ & $2388(12.10)$ & 1.00 (0.94 to 1.07$)$ & 0.9858 & $1.03(0.96$ to 1.11$)$ & 0.3815 \\
\hline 2 years, n (\%) & $884(4.74)$ & $2784(14.11)$ & 1.14 (1.06 to 1.23$)$ & 0.0005 & 1.23 (1.13 to 1.33$)$ & $<0.0001$ \\
\hline 5 years, n (\%) & $1192(6.39)$ & $3787(19.19)$ & 1.20 (1.11 to 1.30$)$ & $<0.0001$ & 1.39 (1.27 to 1.51$)$ & $<0.0001$ \\
\hline \multicolumn{7}{|c|}{ Permanent lack of attachment to the labour market } \\
\hline Index date, n (\%) & $0(0)$ & $0(0)$ & - & - & - & - \\
\hline 6 months, $\mathrm{n}(\%)$ & $33(0.18)$ & $82(0.42)$ & 3.40 (2.36 to 4.90$)$ & $<0.0001$ & 1.90 (1.36 to 2.66$)$ & 0.0002 \\
\hline 12 months, n (\%) & $58(0.31)$ & $173(1.88)$ & $3.63(2.77$ to 4.75$)$ & $<0.0001$ & 2.14 (1.66 to 2.77$)$ & $<0.0001$ \\
\hline 12 months, n (\%) & $12(0.06)$ & $100(0.51)$ & $8.03(4.29$ to 15.05$)$ & $<0.0001$ & 4.67 (2.59 to 8.40$)$ & $<0.0001$ \\
\hline 2 years, $\mathrm{n}(\%)$ & $26(0.14)$ & $207(1.05)$ & 7.67 (5.01 to 11.75$)$ & $<0.0001$ & 4.72 (3.12 to 7.13$)$ & $<0.0001$ \\
\hline 5 years, n (\%) & $118(0.63)$ & $477(2.42)$ & 3.91 (3.17 to 4.82$)$ & $<0.0001$ & 2.62 (2.11 to 3.26$)$ & $<0.0001$ \\
\hline
\end{tabular}

*Prevalence expressed as the total number and percentage of patients and controls experiencing the outcome.

†Generalised estimating equation model with OR of the outcome event in patients compared with controls adjusted for age, gender, municipality, seasonal variation, calendar year, education, income, cohabitation status, ethnicity, comorbidities and preinjury psychiatric diagnosis.

mTBI, mild traumatic brain injury.

For the secondary outcomes, the prevalence of sick listed decreased during follow-up, while the prevalence of limited and permanent lack of attachment to the labour market increased as expected. The proportion of individuals receiving health-related benefits at the index date was also higher for patients compared with controls, and the risk was more than two times higher for patients even after controlling for possible confounders. This may indicate increased morbidity in patients with mTBI prior to the trauma as seen in another Danish study, ${ }^{13}$ and variations in health-seeking behaviour which result in health-related social transfer payments. However, at 6 months, the odds diminished to $30 \%$ and were further decreased during follow-up to $16 \%-20 \%$. Stulemeijer et al found a $76 \%$ full RTW rate at 6 months,${ }^{47}$ de Koning et al found a complete RTW rate of $77 \%$ at 12 months ${ }^{48}$ and Losoi et al also found that 97\% had fully RTW by 12 months after mTBI. ${ }^{10}$ These findings are slightly higher than those reported in this study. However, previous investigations are not directly comparable because there is a lack of consistency in definitions of labour market attachment and RTW measures. RTW is increasingly regarded 


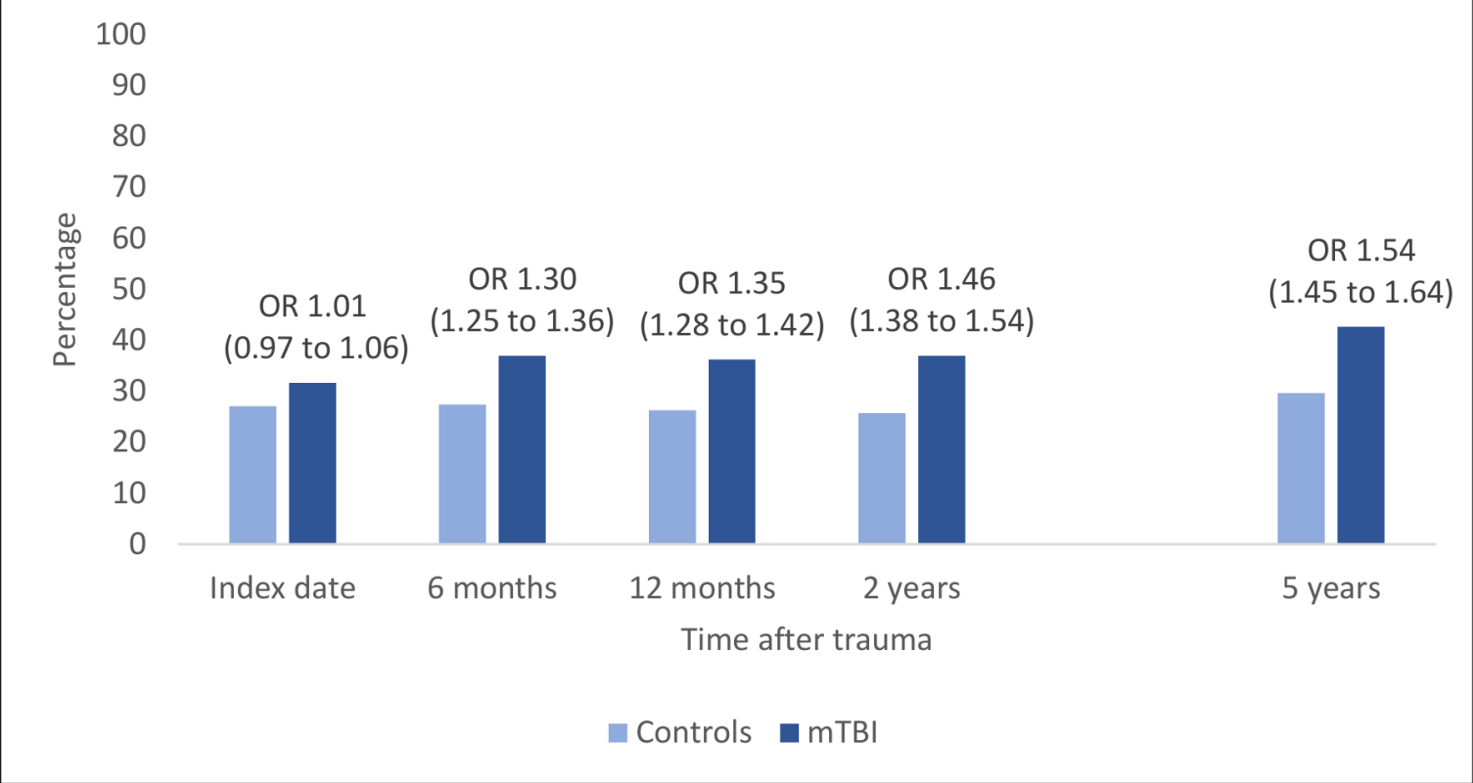

Figure 3 Prevalence and adjusted odds of not attending ordinary work at the index date and up to 5 years after concussion. mTBI, mild traumatic brain injury.

as an evolving process consisting of different phases such as off work, work reentry, retention and advancement. ${ }^{49}$ Additionally, differences between countries in registration of social transfer payments, political legislation and socioeconomic differences can complicate comparison. ${ }^{20}$

Theadom et al found that work productivity was reduced by $15.5 \%$ among patients with mTBI, who had to make job changes to continue working. ${ }^{50}$ Our study found a long-term prevalence of $19 \%$ and increased odds of almost $40 \%$ of limited attachment to the labour market indicating long-term employment restrictions due to health conditions. These results indicate that most patients return to work after mTBI, but a small proportion of patients suffer long-term consequences related to mTBI, preventing them from fully reintegrating into the labour market. Since a previous study indicates an association between increasing length of sickness absence and increasing risk of disability pension, ${ }^{51}$ these patients are at risk of transitioning from temporary to permanent social benefits, meaning an exit from the labour market. For permanent lack of attachment to the labour market, the prevalence in our study was higher for patients even though there were significantly fewer events especially at 6 and 12 months and 2 years, indicating that it takes time to qualify for disability pension in Denmark. The odds of permanent lack of attachment to the labour market were still more than twice as high in the short-term as well as the long-term among patients with mTBI, even when controlled for potential confounders.

Finally, the prevalence of death was higher in patients compared with controls. The odds of death were more than six times higher for patients and subsequently declined during follow-up. This is a surprising result assumed to be predicted by a set of different factors (socioeconomic indicators, comorbidities, etc) than those predicting labour market attachment. Selassie et al found an in-hospital all-cause mortality rate after mTBI of $1.4 \%{ }^{52}$ and Pentland et al found similar results at $0.45 \%$ in a cohort with 21 years of follow-up,,$^{53}$ agreeing with the result found in the present study. Additionally, a Danish study found an increased risk of suicide among patients with mTBI. ${ }^{54}$ Although not the aim of the present study, future research may benefit from exploring the risk factors in excess mortality in patients with mTBI.

\section{Strengths and limitations}

This study applied a register-based design preventing information bias in the collection of data. The DREAM enabled us to estimate point prevalence during 5 years of follow-up and to examine much more diverse labour market outcomes which is infrequent in TBI research. ${ }^{20}$ Furthermore, the sensitivity and specificity of the DREAM is considered high. ${ }^{55}$ Finally, the use of national register data has made it possible to include a large sample size and a matching control group which increased the statistical power. We also adjusted for a wide range of preinjury potential confounders. However, residual confounding such as injury mechanism and psychological effects affecting outcome cannot be ruled out. Patients were extracted from the DNPR. Consequently, we did not have access to patient records, which hindered us to apply the operational case definition for mTBI suggested by WHO. ${ }^{4}$ Even though the DNPR is considered the most comprehensive register of its kind, ${ }^{27}$ its validity and consistency with clinical diagnoses are widely discussed, especially regarding clinical diagnoses and inaccurate coding leading to misclassification. The ICD-9 code (850) for concussion has in several studies been reported as 
frequently used for the classification of $\mathrm{mTBI}^{456}$ but has also shown lack of sensitivity and specificity. ${ }^{4}$ This could also be expected to be the case for ICD-10. Additionally, a large proportion of patients with mTBI are not treated at the hospital, some are treated in primary care settings and some refrain from consulting a physician, ${ }^{57}$ which can lead to low incidence rates and selection bias, limiting the generalisability of the results. ${ }^{58}$

\section{Implications}

A small proportion of patients with mTBI may suffer from persistent postconcussive symptoms for months and years after injury, preventing returning to previous work. ${ }^{17465960}$ This study showed that patients with mTBI have a higher prevalence of receiving social transfer payments compared with the general population postinjury. In Denmark, there are no national guidelines for the treatment and rehabilitation of patients with mTBI. This is in contrast to the guidelines developed for patients suffering more severe forms of TBI. We therefore assume that the treatment trajectory in patients with mTBI is lengthy and inefficient, as it is highly dependent on referrals from general practitioners, insurance companies and the municipalities. Our data suggest that patients with mTBI need a comprehensive and coordinated approach, including the identification of patients at risk of developing persistent postconcussive symptoms and initiation of a treatment plan in a timely fashion. Future research should focus on examining the contributory causes as to why patients with mTBI do not return to work.

\section{CONCLUSIONS}

Most patients returned to work after mTBI. However, a small proportion of patients with mTBI received social transfer payments related to health and work disability to a higher extent than the general population at 5 years postinjury. Additionally, the prevalence of death was increased during follow-up. Initiatives that identify and prevent the progression of persistent postconcussive symptoms should be considered to reduce lack of attachment to the labour market in this patient group.

\section{Author affiliations \\ ${ }^{1}$ Department of Anaesthesia, Centre of Head and Orthopaedics, University Hospital Rigshospitalet, Copenhagen, Denmark \\ ${ }^{2}$ Department of Public Health, The Research Unit for General Practice and Section of General Practice, University of Copenhagen, Copenhagen, Denmark \\ ${ }^{3}$ Department of Occupational and Social Medicine, Copenhagen University Hospital Holbaek, Holbaek, Denmark \\ ${ }^{4}$ Musculoskeletal disorders and physical workload, National Research Centre for the Working Environment, Copenhagen, Denmark \\ ${ }^{5}$ Department of intensive care, Centre for Cancer and Organ Diseases, University Hospital Rigshospitalet, Copenhagen, Denmark \\ ${ }^{6}$ Department of Psychology, University of Copenhagen, Copenhagen, Denmark ${ }^{7}$ Department of Neurology, University Hospital Bispebjerg-Frederiksberg, Copenhagen, Denmark}

Contributors All authors participated in the study design, interpretation of the data, revising it critically and the final approval of the manuscript to be published. HJG obtained the funding, drafted the protocol and manuscript and collaborated with VS on performing the statistical analyses. AM, LLA, JK, IE and HMR participated in the study design and conceptualisation.

Funding This work was supported by the Research Foundation, Rigshospitalet (E-22260-03) (E-23473-01), the Danish Health Foundation (Helsefonden) (16-B0050) and the Aase and Ejnar Danielsen's Foundation (20-000054).

Competing interests None declared.

Provenance and peer review Not commissioned; externally peer reviewed.

Data sharing statement No additional data are available.

Open access This is an open access article distributed in accordance with the Creative Commons Attribution Non Commercial (CC BY-NC 4.0) license, which permits others to distribute, remix, adapt, build upon this work non-commercially, and license their derivative works on different terms, provided the original work is properly cited, appropriate credit is given, any changes made indicated, and the use is non-commercial. See: http://creativecommons.org/licenses/by-nc/4.0/.

\section{REFERENCES}

1. Carroll LJ, Cassidy JD, Holm L, et al. Methodological issues and research recommendations for mild traumatic brain injury: the WHO Collaborating Centre Task Force on Mild Traumatic Brain Injury. $J$ Rehabil Med 2004:113-25.

2. \&NA; \&NA; . Definition of mild traumatic brain injury. J Head Trauma Rehabil 1993;8:86-7.

3. Katz DI, Cohen SI, Alexander MP. In: Grafman J, Salazar AM, eds. Handbook of Clinical Neurology, Vol. 127 (3rd series) Traumatic Brain Injury, Part I, 2015:129-242.

4. McCrory P, Meeuwisse WH, Aubry M, et al. Consensus statement on concussion in sport: the 4th International Conference on Concussion in Sport held in Zurich, November 2012. Br J Sports Med 2013;47:250-8.

5. Undén L, Calcagnile O, Undén J, et al. Validation of the Scandinavian guidelines for initial management of minimal, mild and moderate traumatic brain injury in adults. BMC Med 2015;13:292.

6. Levin HS, Diaz-Arrastia RR. Diagnosis, prognosis, and clinical management of mild traumatic brain injury. Lancet Neurol 2015;14:506-17.

7. van der Naalt J, Timmerman ME, de Koning ME, et al. Early predictors of outcome after mild traumatic brain injury (UPFRONT): an observational cohort study. Lancet Neurol 2017;16:532-40.

8. Cassidy JD, Carroll LJ, Peloso PM, et al. Incidence, risk factors and prevention of mild traumatic brain injury: results of the WHO Collaborating Centre Task Force on Mild Traumatic Brain Injury. J Rehabil Med 2004:28-60.

9. Engberg AW, Teasdale TW. [Epidemiology and treatment of head injuries in Denmark 1994-2002, illustrated with hospital statistics]. Ugeskr Laeger 2007;169:199-203.

10. Losoi H, Silverberg ND, Wäljas M, et al. Recovery from Mild Traumatic Brain Injury in Previously Healthy Adults. J Neurotrauma 2016;33:766-76.

11. Dumke HA. Posttraumatic Headache and Its Impact on Return to Work After Mild Traumatic Brain Injury. J Head Trauma Rehabil 2017;32:E55-E65.

12. Ponsford J, Willmott $C$, Rothwell $A$, et al. Factors influencing outcome following mild traumatic brain injury in adults. $J$ Int Neuropsychol Soc 2000;6:568-79.

13. Galili SF, Bech BH, Vestergaard C, et al. Use of general practice before and after mild traumatic brain injury: a nationwide populationbased cohort study in Denmark. BMJ Open 2017;7:e017735.

14. Rutherford WH, Merrett JD, McDonald JR. Symptoms at one year following concussion from minor head injuries. Injury 1979;10:225-30.

15. Rees PM. Contemporary issues in mild traumatic brain injury. Arch Phys Med Rehabil 2003;84:1885-94.

16. Edna $\mathrm{TH}$, Cappelen J. Late post-concussional symptoms in traumatic head injury. An analysis of frequency and risk factors. Acta Neurochir 1987;86:12-17.

17. Ponsford J, Cameron P, Fitzgerald M, et al. Predictors of postconcussive symptoms 3 months after mild traumatic brain injury. Neuropsychology 2012;26:304-13.

18. Kristman VL, Cote P, Hogg-Johnson S, et al. The burden of work disability associated with mild traumatic brain injury in Ontario Compensated Workers: a prospective cohort st udy !2009-11-16 !2010-02-21 !2010-03-16 !. The Open Occupational Health \& Safety Journal 2010;2:1-8.

19. Wäljas M, Iverson GL, Lange RT, et al. Return to work following mild traumatic brain injury. J Head Trauma Rehabil 2014;29:443-50. 
20. Cancelliere C, Kristman VL, Cassidy JD, et al. Systematic review of return to work after mild traumatic brain injury: results of the International Collaboration on Mild Traumatic Brain Injury Prognosis. Arch Phys Med Rehabil 2014:95:S201-9.

21. Pransky G, Gatchel R, Linton SJ, et al. Improving return to work research. J Occup Rehabil 2005;15:453-7.

22. Young AE, Wasiak R, Roessler RT, et al. Return-to-work outcomes following work disability: stakeholder motivations, interests and concerns. J Occup Rehabil 2005;15:543-56.

23. Sveen U, Søberg HL, Østensjø S. Biographical disruption, adjustment and reconstruction of everyday occupations and work participation after mild traumatic brain injury. A focus group study. Disabil Rehabil 2016;38:2296-304.

24. Friedland JF, Dawson DR. Function after motor vehicle accidents: a prospective study of mild head injury and posttraumatic stress. $J$ Nerv Ment Dis 2001;189:426-34.

25. Mani K, Cater B, Hudlikar A. Cognition and return to work after mild/moderate traumatic brain injury: a systematic review. Work 2017;58:51-62

26. Pedersen CB. The Danish Civil Registration System. Scand J Public Health 2011;39:22-5.

27. Lynge E, Sandegaard JL, Rebolj M. The Danish National Patient Register. Scand J Public Health 2011;39:30-3.

28. Beskæftigelsesministeriet [The Ministry of Employment]. Bekendtgørelse om efterlønsbevis, udskydelsesreglen og skattefri præmie m.v BEK nr 4 af 02/01/2017 Gældende. https://www. retsinformation.dk/forms/R0710.aspx?id=186130 (Accessed 8 Aug 2018).

29. Noonan VK, Thorogood NP, Fingas M, et al. The validity of administrative data to classify patients with spinal column and cord injuries. J Neurotrauma 2013;30:173-80.

30. National Center for Injury Prevention and Control. Report to Congress on Mild Traumatic Brain Injury in the United States: Steps to prevent a Serious Public Health Problem. 2003 https://www.cdc. gov/traumaticbraininjury/pdf/mtbireport-a.pdf (Accessed 8 Aug 2018).

31. Cassidy JD, Cancelliere C, Carroll LJ, et al. Systematic review of selfreported prognosis in adults after mild traumatic brain injury: results of the International Collaboration on Mild Traumatic Brain Injury Prognosis. Arch Phys Med Rehabil 2014;95:S132-51.

32. Styrelsen for Arbejdsmarked og Rekruttering [Danish Agency for Labour Market and Recruitment]. DREAM version 41. 2018 https:// www.dst.dk/-/media/Kontorer/13-Forskning-og-Metode/DREAMkoder-version-41.docx?la=da.

33. Beskæftigelsesministeriet [The Ministry of Employment]. Bekendtgørelse af lov om sygedagpenge. 2010/1 LSF 68. http:// www.retsinformation.dk/eli/ft/201012L00068 (Accessed 03 Jan 2019).

34. Beskæftigelsesministeriet [The Ministry of Employment]. Bekendtgørelse af lov om sygedagpenge LBK nr 653 af 26/06/2012 Historisk. https://www.retsinformation.dk/Forms/R0710.aspx?id= 142423\#Afs6 (Accessed 03 Jan 2019).

35. Beskæftigelsesministeriet [The Ministry of Employment]. Bekendtgørelse af lov om en aktiv beskæftigelsesindsats LBK nr 685 af 29/06/2005 Historisk. https://www.retsinformation.dk/Forms/ R0710.aspx?id=30223 (Accessed 03 Jan 2019).

36. . Beskæftigelsesministeriet [The Ministry of Employment]Bekendtgørelse af lov om social pension. LBK $\mathrm{nr} 783 \mathrm{af}$ 09/07/2012. https://www.retsinformation.dk/Forms/R0710.aspx?id= 142132 (Accessed 03 Jan 2019).

37. Ministry for Economic Affairs and the Interior. Structural reform. 2007 http://english.oim.dk/responsibilities-of-the-ministry/economics-ofmunicipalities-and-regions/structural-reform/.

38. Hannerz H, Mortensen OS, Poulsen OM, et al. Time trend analysis of return to work after stroke in Denmark 1996-2006. Int J Occup Med Environ Health 2012;25:200-4.

39. Rao DP, McFaull S, Thompson W, et al. Trends in self-reported traumatic brain injury among Canadians, 2005-2014: a repeated cross-sectional analysis. CMAJ Open 2017:5:E301-7.
40. Baadsgaard M, Quitzau J. Danish registers on personal income and transfer payments. Scand J Public Health 2011;39:103-5.

41. Jensen VM, Rasmussen AW. The Danish Civil Registration System. Scand J Public Health 2011;39:91-4.

42. Statistics Denmark. Households, Families and Children. Secondary Households, Families and Children. 2017 http://www.dst.dk/en/ Statistik/dokumentation/documentationofstatistics/householdsfamilies-and-children.

43. Thygesen SK, Christiansen CF, Christensen S, et al. The predictive value of ICD-10 diagnostic coding used to assess Charlson comorbidity index conditions in the population-based Danish National Registry of Patients. BMC Med Res Methodol 2011;11:83.

44. Charlson ME, Pompei P, Ales KL, et al. A new method of classifying prognostic comorbidity in longitudinal studies: development and validation. J Chronic Dis 1987:40:373-83.

45. Pedersen $\mathrm{P}$, Lund $\mathrm{T}$, Lindholdt $\mathrm{L}$, et al. Labour market trajectories following sickness absence due to self-reported all cause morbidity-a longitudinal study. BMC Public Health 2016;16:337.

46. Carroll LJ, Cassidy JD, Cancelliere C, et al. Systematic review of the prognosis after mild traumatic brain injury in adults: cognitive, psychiatric, and mortality outcomes: results of the International Collaboration on Mild Traumatic Brain Injury Prognosis. Arch Phys Med Rehabil 2014;95:S152-73.

47. Stulemeijer M, van der Werf S, Borm GF, et al. Early prediction of favourable recovery 6 months after mild traumatic brain injury. $J$ Neurol Neurosurg Psychiatry 2008;79:936-42.

48. de Koning ME, Scheenen ME, van der Horn HJ, et al. Prediction of work resumption and sustainability up to 1 year after mild traumatic brain injury. Neurology 2017;89:1908-14.

49. Steenstra IA, Lee H, de Vroome EM, et al. Comparing current definitions of return to work: a measurement approach. J Occup Rehabil 2012;22:394-400.

50. Theadom A, Barker-Collo S, Jones K, et al. Work limitations 4 years after mild traumatic brain injury: a cohort study. Arch Phys Med Rehabil 2017;98:1560-6.

51. Lund T, Kivimäki M, Labriola $\mathrm{M}$, et al. Using administrative sickness absence data as a marker of future disability pension: the prospective DREAM study of Danish private sector employees. Occup Environ Med 2008;65:28-31.

52. Selassie AW, Fakhry SM, Ford DW. Population-based study of the risk of in-hospital death after traumatic brain injury: the role of sepsis. J Trauma 2011:71:1226-34

53. Pentland B, Hutton LS, Jones PA. Late mortality after head injury. $J$ Neurol Neurosurg Psychiatry 2005;76:395-400.

54. Madsen T, Erlangsen A, Orlovska S, et al. Association between Traumatic Brain Injury and Risk of Suicide. JAMA 2018;320:580-8.

55. Stapelfeldt CM, Jensen C, Andersen NT, et al. Validation of sick leave measures: self-reported sick leave and sickness benefit data from a Danish national register compared to multiple workplace-registered sick leave spells in a Danish municipality. BMC Public Health 2012;12:661.

56. Chen AY, Colantonio A. Defining neurotrauma in administrative data using the International Classification of Diseases Tenth Revision. Emerg Themes Epidemiol 2011;8:4.

57. Mannix R, O'Brien MJ, Meehan WP. The epidemiology of outpatient visits for minor head injury: 2005 to 2009. Neurosurgery 2013;73:129-34.

58. Kristman VL, Borg J, Godbolt AK, et al. Methodological issues and research recommendations for prognosis after mild traumatic brain injury: results of the International Collaboration on Mild Traumatic Brain Injury Prognosis. Arch Phys Med Rehabil 2014;95:S265-77.

59. van der Naalt J, van Zomeren AH, Sluiter WJ, et al. One year outcome in mild to moderate head injury: the predictive value of acute injury characteristics related to complaints and return to work. J Neurol Neurosurg Psychiatry 1999;66:207-13.

60. Graff HJ, Siersma V, Møller A, et al. Premorbid risk factors influencing labour market attachment after mild traumatic brain injury: a national register study with long-term follow-up. BMJ Open 2019:e027297. 